
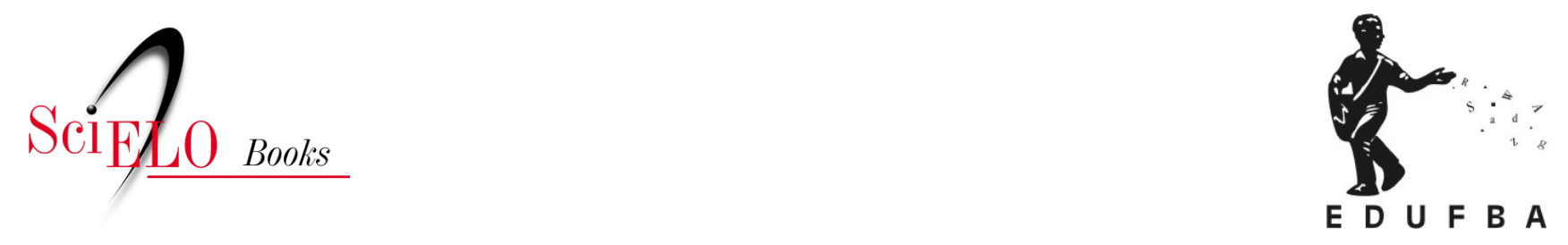

\title{
O trabalho dos fisioterapeutas em UTI entre o real e o prescrito
}

\author{
Rosângela Cunha da Rocha \\ Mônica Angelim Gomes de Lima \\ Rita de Cássia Pereira Fernandes
}

\section{SciELO Books / SciELO Livros / SciELO Libros}

ROCHA, R.C., LIMA, M.A.G., and FERNANDES, R.C.P. O trabalho dos fisioterapeutas em UTI entre o real e o prescrito. In: FERNANDES, R.C.P., LIMA, M.A.G., and ARAÚJO, T.M., comps. Tópicos em saúde, ambiente e trabalho: um olhar ampliado [online]. Salvador: EDUFBA, 2014, pp. 21-51. ISBN: 978-65-5630-012-2. https://doi.org/10.7476/9786556300122.0004.

\section{International license.}

Todo o conteúdo deste trabalho, exceto quando houver ressalva, é publicado sob a licença Creative Commons Atribição 4.0. 


\section{O trabalho dos fisioterapeutas em UTI: entre o real e o prescrito}

Rosângela Cunha da Rocha Mônica Angelim Gomes de Lima Rita de Cássia Pereira Fernandes

\section{Introdução}

O setor de saúde orientado pela lógica da reestruturação produtiva tem instituído reformas organizacionais para atender a meta de ampliar a assistência através da redução de gastos e adequação dos recursos humanos. (GUEDES; LIMA; ASSUNÇÃO, 2005) Os processos de trabalho no âmbito da assistência à saúde sofreram transformações da forma de cuidados simplificados para uma abordagem e utilização de equipamentos mais complexos. Dessa maneira, gerou-se a necessidade de diversificação e especialização da força de trabalho. (SIQUEIRA; WATANABELL; VENTOLA, 1995)

De acordo com Gaspar (1997), os hospitais são instituições que oferecem consideravelmente maior possibilidade de agravos à saúde dos trabalhadores, entre todas as instituições de saúde, por apresentarem condições complexas de trabalho. No tocante a este ambiente, os riscos mais citados na literatura e que se revestem de especial significado são os biológicos. (CAIXETA; BARBOSA-BRANCO, 2005) Entre as infecções de maior risco para os trabalhadores nestes ambientes encontram-se as transmitidas por sangue e outros fluidos corpóreos, como: a Hepatite B, a Hepatite C, a Síndrome da Imunodeficiência Adquirida (SIDA), a Tuberculose, a Varicela, a Herpes-zoster, o Sarampo, entre outras. (RESENDE; FORTALEZA, 2001; PANHOTRA; SAXENA, AL-MULHIM, 2005) 
Dentre os fatores que aumentam a vulnerabilidade dos trabalhadores de saúde aos riscos biológicos, destacam-se: a complexidade de assistência prestada aos pacientes, a exigência de ritmos acelerados de produção, procedimentos com possibilidade de contato com sangue e outros fluidos corpóreos, o pouco investimento das instituições de saúde na manutenção dos meios de trabalho (materiais e equipamentos) e em medidas de proteção coletiva, entre outros. (BARBOSA, 1989; BULHÕES, 1998; SARQUIS, 2007)

Em particular, as Unidades de Terapia Intensiva (UTIs) se revestem de especial significado por se tratarem de ambientes, no espaço hospitalar, destinados a prestar assistência a pacientes criticamente enfermos, comumente com alto grau de dependência de assistência direta da equipe de saúde. Puro e colaboradores (2001) destacam a UTI como uma das áreas de maior risco de exposição dos trabalhadores aos agentes biológicos nas instituições hospitalares. Associado a isto, é uma unidade onde a incorporação de novas tecnologias e os processos de trabalho ampliam a vulnerabilidade destes profissionais.

O fisioterapeuta, como componente das equipes de saúde das UTIs, ao realizar as suas atividades cotidianas, depara-se com diversas situações que podem comprometer a sua saúde, não apenas relacionadas com o meio físico propriamente dito, com os instrumentos de trabalho, mas situações relativas às relações sociais e à organização do trabalho.

Silva e colaboradores (2008), desenvolvendo estudo em hospital universitário, constataram que os fisioterapeutas apresentam 4,6 vezes maior probabilidade de serem colonizados por microrganismos multirresistentes na execução de suas atividades, quando comparados com outros profissionais do mesmo setor. Entre as atividades realizadas pelos fisioterapeutas na UTI e que podem aumentar a exposição destes trabalhadores aos riscos biológicos estão às mobilizações e posicionamentos de pacientes potencialmente infectados ou colonizados, manobras de hiperinsuflação manual dos pulmões, exercícios de tosse, aspirações de secreções pulmonares, entre outras. Guttenberg e Spickett (2009) constataram que no ambiente hospitalar as causas de maior exposição dos fisioterapeutas aos riscos biológicos são as situações de contingências $(33,3 \%)$, as fontes contaminadas com sangue e outros fluidos corpóreos $(28,4 \%)$, e fatores organizacionais $(22,2 \%)$. 
A proposta do presente estudo é descrever as ações práticas dos fisioterapeutas diante das limitações de condições materiais e dos riscos biológicos em uma UTI. Pretende-se compreender a dinâmica das interações sociais nas práticas cotidianas dos fisioterapeutas diante dos riscos biológicos, através dos seus depoimentos.

\section{Métodos}

O estudo abrangerá os pressupostos da Etnometodologia, que define o risco como um fenômeno socialmente construído e negociado como parte de interações no cotidiano de trabalho destes profissionais. A Etnometodologia, a partir da análise das interações sociais, e a Análise Ergonômica do Trabalho (AET) contribuirão para o entendimento dos modos operatórios e estratégias que os fisioterapeutas utilizam para produzir ordem de forma detalhada e sequencial, considerando as contingências nos seus locais de trabalho.

A Etnometodologia e a AET são correntes teórico-metodológicas com vertentes na sociologia, antropologia e psicologia da cognição, as quais privilegiam a ação situada em contextos organizacionais. (THERRIEN; CARVALHO, 2009) De tal modo, a aproximação com estas duas correntes mostra-se oportuna para desvelar o fenômeno abordado neste estudo, que se refere à ação prática dos sujeitos de fisioterapia em uma UTI.

A designação 'ação situada' foi introduzida por Suchman (1987), que enfatiza a ideia de que cada curso da ação depende essencialmente das circunstâncias materiais e sociais em que estas ocorrem. Para este autor, mais do que atentar para a ação abstrata longe de sua situação e representá-la como racional, deve-se estudar como as pessoas usam as suas circunstâncias para alcançar a ação inteligente. (SUCHMAN, 1987, p. 50)

Para Coulon (1995), nos estudos do trabalho, é importante abordar as instruções que regem as ações dos atores sociais, ou seja, as ações e raciocínios práticos e especificar em que se constituem as normas e regras para assim definir os seus significados. Deve-se considerar que a ação é uma instrução que é colocada em prática. Contudo, faz-se necessário considerar que as regras nunca observam as contingências práticas, violá-las pode significar, para os membros, permitir norma- 
lizar o curso da ação. Seguir procedimentos de maneira competente não diz respeito, portanto, à conformidade ou desvio em relação aos procedimentos preestabelecidos, mas ao julgamento que se faz acerca da pertinência do procedimento em determinada situação.

Em direção semelhante, a análise ergonômica do trabalho (AET) refere-se à análise da atividade do trabalhador em situações reais de trabalho, ou seja, à compreensão de como o homem realiza o trabalho prescrito pela organização em situações reais. (ABRAHÃO, 2000) De acordo com Wisner (1994), a AET nasce como abordagem sobre o trabalho que passa a incluir o ponto de vista do trabalhador em situação de trabalho real. "Não se trata mais de fazer com que a tarefa seja descrita pela direção e sim analisar as atividades do trabalho". (WISNER, 1994, p. 93) O inventário das diferenças entre o trabalho prescrito e o real se faz importante para dar ênfase ao que é difícil e, muitas vezes, impraticável de se realizar. A tarefa refere-se ao que está prescrito pela organização, incluindo os objetivos, as normas, os meios fornecidos e as condições de trabalho. A atividade consiste em como o trabalhador realiza a tarefa ou trabalho prescrito, observando-se o objetivo proposto e os meios disponíveis nas condições reais. (LIMA, 1995)

Existem variações nas situações de trabalho e estas são permeadas pelas características individuais dos trabalhadores, pela sua competência, pelas metas de produção e pelos meios social e tecnológico. (ABRAHÃO, 2000) Assim sendo, a noção de variabilidade na AET é central, pois o trabalho nunca é o resultado imediato das normas prescritas, mas pressupõe um percurso de elaboração e reorganização por parte do trabalhador, simultaneamente cognitivo e situado na prática. (LIMA, 1995)

Como estratégia para realizar estudos nos locais de trabalho, a Etnometodologia e a AET compartilham dos princípios da metodologia etnográfica. Segundo Wisner (1994), a AET pode ser conhecida como uma pesquisa etnográfica, se voltada para detecção das dificuldades impostas pelo ambiente de trabalho e pelas exigências pragmáticas que atrapalham as atividades do trabalhador.

Nos estudos em Etnometodologia Have (2004) destaca que não existem métodos específicos e sugere as seguintes estratégias para acessar o detalhe das atividades nos estudos nos locais de trabalho: observar o que as pessoas fazem, tanto as experiências novas como as 
atividades de rotina; observar os trabalhadores, tanto os experientes como os novatos; observar como os trabalhadores seguem as instruções e o seu aprendizado; observar e gravar de forma interativa, inclusive as "mímicas incompreensíveis" e as atividades dos atores; observar e gravar as tarefas de aprendizado; combinar a etnografia e gravação no local de trabalho.

Assim, ao se destacar o papel ativo dos atores sociais, os pesquisadores devem ser capazes de contextualizar suas descrições a partir da lógica, dos raciocínios específicos e das situações de vida prática desses sujeitos.

\section{Inserção e desenvolvimento em campo}

Após concordância dos gestores do hospital com a realização do estudo, o projeto de pesquisa foi encaminhado ao Comitê de Ética em Pesquisa da Maternidade Climério de Oliveira e foi aprovado conforme Parecer n. ${ }^{\circ}$ 045/2009.

No primeiro contato com os sujeitos da pesquisa se expôs o projeto, os objetivos e os métodos a serem utilizados, ressaltaram-se os procedimentos éticos envolvidos e se convidou os fisioterapeutas a participarem de forma voluntária do estudo. Todos os participantes desta pesquisa receberam um código no intuito de não permitir a sua identificação e assinaram o Termo de Consentimento Livre e Esclarecido.

Nas primeiras visitas ao campo, procurou-se entender o funcionamento da UTI. As primeiras entrevistas foram feitas com a chefia do Serviço de fisioterapia e com o coordenador de fisioterapia da UTI. Estas entrevistas foram semiestruturadas, a partir das quais se objetivou conhecer os aspectos organizacionais do Serviço de fisioterapia na UTI. Utilizou-se um roteiro como guia, contudo, vale observar que este não foi utilizado de forma rígida, foram acrescentadas novas questões que surgiram na construção interacional com os entrevistados.

Foram realizadas também entrevistas com os componentes do Serviço de Controle de Infecção Hospitalar (SCIH), da Comissão Interna de Prevenção de Acidentes (CIPA) e do Serviço de Medicina Ocupacional do Hospital (SESAO) que tiveram como conteúdo a forma de Gestão do Risco na Instituição com ênfase nas ações voltadas para a UTI. 
Foram entrevistados vários interlocutores (fisioterapeutas, gestores, cursistas) e fez-se consulta aos documentos acerca do trabalho dos fisioterapeutas na UTI.

Realizou-se, nesta primeira etapa, um estudo global do funcionamento da UTI, da organização do trabalho, da produção e dos determinantes das tarefas.

Após essa etapa, iniciaram-se as observações, considerando as variáveis: deslocamento dos fisioterapeutas, direção do olhar (ao buscar informação), comunicação (com os colegas, com a chefia e com a pesquisadora), posturas, ações e tempo, que foram registradas em diário de campo. Observaram-se a sequência de ações, as modificações do modo operatório ditadas pelas variabilidades do processo de trabalho, dos pacientes, variabilidades entre os próprios fisioterapeutas, os padrões de comportamento (estratégias) adotados na execução das tarefas.

Foram acompanhadas as passagens de plantão da equipe de fisioterapia, as visitas, as rotinas diárias, os atendimentos fisioterapêuticos na UTI e fora desta, a evolução em prontuários, as discussões clínicas e os encontros ocorridos na copa e na sala de fisioterapia.

A partir das observações gerais, realizou-se o acompanhamento de um profissional por período de observação, com o objetivo de apreender a dinâmica da atividade de forma detalhada. Assim, foi possível realizar a crônica da atividade do fisioterapeuta na UTI. Os sujeitos da pesquisa nesta etapa foram 11 fisioterapeutas assistenciais da UTI, sete mulheres e quatro homens, com idade entre 23 e 37 anos e tempo de serviço na UTI bastante variado, mas com uma média de cinco anos.

O trabalho em campo ocorreu durante os horários da manhã, tarde e noite - incluindo feriados e finais de semana - considerando-se as variações no volume de trabalho e a diversidade das tarefas. A média de permanência diária na UTI foi de cinco horas e ocorreu entre os meses de julho e dezembro de 2009. O tempo total de observação correspondeu há 85 horas e 41 minutos. O tempo total de entrevistas não situadas correspondeu há 3 horas e 5 minutos.

$\mathrm{Na}$ observação participante, procurou-se apreender, em profundidade, a sequência das verbalizações, a atividade ordinária dos fisioterapeutas, suas estratégias e discurso tácito diante dos riscos biológicos e da insuficiência dos meios de trabalho. Interessou-se não apenas pelo discurso dos atores sociais, mas também pela sua metalinguagem de- 
sordenada, os acidentes, as contingências que se misturavam à sua prática cotidiana.

As entrevistas situadas foram iniciadas após um período de familiarização com o campo e contato com o seu cotidiano. A intenção da entrevista foi complementar os dados das observações. Desse modo, realizaram-se entrevistas situadas e/ou consecutivas às atividades dos trabalhadores. Estas foram abertas, com conteúdo organizado de acordo com as questões que surgiram em campo, pautadas no interesse da investigação e no curso das atividades.

Guérin e colaboradores (2001, p.156) fazem a seguinte descrição sobre as verbalizações simultâneas e consecutivas:

As verbalizações simultâneas apresentam o interesse de produzir explicações no próprio contexto da atividade. As condições concretas de seu exercício são apresentadas [...]. O operador está em "situação" para expressar-se, o ergonomista em "situação" para compreender [...]. As verbalizações consecutivas, por seu lado, apresentam o interesse em preservar o desenvolvimento normal da atividade. São geralmente coletadas apresentando ao operador o resultado de observações [...]. (GUÉRIN et al., 2001)

Para a validação das informações obtidas, retornou-se ao campo para autoconfrontação das situações observadas, em que os sujeitos da pesquisa foram convidados a falar sobre o seu próprio comportamento, a partir da descrição feita. Os comentários e impressões destes sobre as situações foram anotados no diário de campo.

Como resultado de todas estas etapas, foi estabelecido o diagnóstico de que os fisioterapeutas utilizam estratégias para lidar com os riscos biológicos e as limitadas condições materiais na execução de suas atividades na UTI.

\section{Resultados e discussão}

A Unidade de Terapia Intensiva Geral de um Hospital Universitário (HU) em Salvador, Bahia, destina-se a uma clientela composta de pacientes internados oriundos das enfermarias do hospital ou procedentes de outros hospitais que vêm encaminhados pela Central de Regulação do SUS. 
O HU é uma unidade hospitalar de alta complexidade, pública, geral, de grande porte, com capacidade de internação plena de 276 leitos. A capacidade da UTI é para 16 leitos, porém, na época do estudo, funcionavam dez. Seu espaço físico está dividido em área administrativa, área de internamento de pacientes, vestiários e copa.

A unidade disponibiliza, como recursos tecnológicos para o cuidado dos pacientes criticamente enfermos, respiradores, bombas infusoras, monitores de dados vitais, desfibriladores, carro de urgência equipado para ressuscitação cardiorrespiratória, entre outros. Por vezes, o quantitativo de materiais de consumo (luvas, roupas de cama, roupas privativas e para os pacientes, sabão para lavagem das mãos, entre outros) é insuficiente. Não são infrequentes reclamações acerca da qualidade e do quantitativo dos materiais e equipamentos presentes na UTI, a exemplo dos Equipamentos de Proteção Individual (EPI), respiradores, oxímetros, o que gera esforço extra, exigindo criatividade e adaptação dos membros da UTI para realizar o seu trabalho.

A equipe de profissionais que atua na UTI é composta por médicos, enfermeiros, técnicos de enfermagem, fisioterapeutas, nutricionistas, auxiliar administrativo, coordenador médico de enfermagem e de fisioterapia, além de docentes de ambas as áreas e outros profissionais que interagem diariamente esta Unidade.

Nos plantões diurnos, a equipe, geralmente, compõe-se de: um médico plantonista, quatro enfermeiras, quatro enfermeiras residentes, oito técnicos de enfermagem, dois fisioterapeutas, quatro cursistas de fisioterapia. Nos plantões noturnos, há um médico plantonista, duas enfermeiras, oito técnicos e um fisioterapeuta.

A assistência aos pacientes ocorre durante 24 horas ininterruptas. Os profissionais se revezam em três turnos de trabalho: o plantão da manhã (7 às 13h), o plantão da tarde (13 às 19h) e o plantão noturno (19 às 7h), com carga horária semanal variando entre 24, 30 e 40 horas semanais, a depender da categoria profissional.

Pela manhã o ritmo de trabalho das equipes é intenso; acontecem banhos, avaliações, prescrições, procedimentos de todas as equipes, inclusive da de fisioterapia. Os diálogos geralmente são a respeito do quadro dos pacientes e das tarefas assistenciais. O ritmo é menor no final da manhã, geralmente entre $12 \mathrm{~h} 30$ e $13 \mathrm{~h}$, quando ocorrem trocas de plantões entre as equipes e parada para almoço. 
O número de pessoas por equipe, principalmente de estudantes que circulam no ambiente da UTI, é grande e muitas vezes torna-se crítico, especialmente no período da manhã, o que interfere na circulação dos profissionais e na execução de suas tarefas.

No trabalho diurno, há poucos momentos para o descanso e estes geralmente ocorrem no horário de visita de familiares, associados à escrita em prontuários e discussões com os cursistas, ou nos horários de almoço.

No período da tarde, geralmente, ocorrem menos procedimentos, contudo, pode tornar-se crucial, com grande restrição de tempo para o fisioterapeuta realizar suas tarefas, quando há somente um fisioterapeuta de plantão na UTI, por remanejamento do seu colega para outras unidades do HU, em caso de desfalques na escala por doença ou por outros motivos.

O plantão noturno inicia-se às $19 \mathrm{~h}$, quando um dos fisioterapeutas do dia passa o plantão para o seu colega que complementará 24 horas ou para o colega que está chegando para o turno. À noite, disponibiliza-se um plantonista de fisioterapia para dez pacientes e prestação de assistência complementar nas unidades de internamento; nesse período, há um momento para descanso, o que pode acontecer ou não a depender da ocorrência de contingências durante o plantão.

Um fato peculiar desse serviço é a forma de contratação dos fisioterapeutas, havendo concursados pela Universidade e pela Secretaria de Saúde do Estado, contratados pela Fundação de Apoio à Pesquisa e Extensão (FAPEX) e bolsistas desta mesma Fundação. Os múltiplos tipos de vínculos dentro de uma mesma instituição podem gerar diferentes formas de gestão do trabalho e repercussões sobre a saúde do trabalhador.

Observa-se, assim, um processo de flexibilização das relações de trabalho no Hospital em estudo. De acordo com Baraldi e colaboradores (2008), este tipo de relação de trabalho no Brasil, costuma ocorrer no setor de saúde, nas situações em que o principal empregador é o Estado (Municípios, Estado e União) em decorrência de um duplo movimento: por ausência de concursos públicos e pela utilização intensiva de contratação de pessoas através de Organismos Internacionais, Organizações Não-Governamentais (ONGs), Organização da Sociedade Civil de Interesse Público (OSCIP), Cooperativas, entre outras Organizações. 
Para Druck (1999), a contratação através de terceiros tem implicado em um processo de precarização dentro e fora das empresas. No interior das empresas, este processo interfere nas relações de trabalho, quando há transferência dos custos e obrigações trabalhistas para terceiros, gerando duas categorias de servidores: os efetivos (de primeira classe) e os subcontratados (de segunda classe), no que se refere às condições de trabalho e aos salários.

No tocante aos riscos ocupacionais, Borges e Franco (1997) chamam atenção para o fato de que o processo de terceirização aumenta os riscos para acidentes no trabalho e desenvolvimento de doenças pelos trabalhadores, além da falta de proteção destes, porquanto a responsabilidade de garantir a saúde e a segurança é, geralmente, transferida para terceiros.

Outro fato que chama a atenção na UTI são os múltiplos vínculos dos fisioterapeutas com outras instituições. Isto gera uma quantidade elevada de horas trabalhadas no mês. A maioria dos fisioterapeutas desta UTI acumula carga horária mensal de 240 horas e alguns atingem até 360 horas de serviço. Isto é reflexo de um mercado de trabalho complexo e desigual que impõe baixos salários, demandando, o acúmulo de vários empregos.

\section{O fisioterapeuta na dinâmica da UTI}

O fisioterapeuta na assistência aos pacientes internados, presta cuidados respiratórios e motores, uma vez que, com frequência, os pacientes neste ambiente estão internados por longo período e sob ventilação artificial.

A reexpansão pulmonar, a remoção de secreções e a mobilização dos pacientes são as principais técnicas utilizadas, assim como a participação nos ajustes e instituição da ventilação mecânica, do desmame ventilatório e das extubações.

Diversos estudos mostram a importância das atividades dos fisioterapeutas na UTI, destacando-se a redução do tempo de permanência na ventilação mecânica; redução dos custos da UTI e da estadia no Hospital; redução da ansiedade do paciente durante o desmame do respirador; rápida mobilização com redução dos efeitos da imobilidade no leito e melhoria da independência funcional dos pacientes in- 
ternados. (ELY; BAKER; DUNGAN, 1996; HORST et al.,1998; HALL; WOOD,1987 DEAN; ROSS 1992; DEAN, 1994) Segundo Richardson (1999), o conhecimento profissional do fisioterapeuta na sua prática cotidiana é consolidado em uma dinâmica contextual, a partir de sua experiência pessoal, da capacidade de sintetizar e interpretar os fatos e assim definir a sua atuação.

Os membros do grupo adquirem uma perspectiva compartilhada através de meios que tácita ou explicitamente negociam e interagem. Não é incomum para o fisioterapeuta, ao olhar para os movimentos respiratórios de um paciente que se encontra na ventilação artificial, perceber que este necessita ser abordado. Ao pegar o seu estetoscópio para auscultá-lo rapidamente, o seu colega, por sua vez, já se aproxima do leito ajudando-o nas condutas e nos ajustes ventilatórios. Assim, ambos normalizam e restabelecem um movimento torácico próximo ao aceitável.

É no seu cotidiano que estes se deparam com situações em que cuidar do paciente é prioridade, muitas vezes em detrimento dos cuidados com o seu próprio corpo e com a sua saúde. O primeiro compromisso estabelecido é com seu paciente, como na cena descrita: o (a) fisioterapeuta é chamado durante um procedimento de traqueostomia na UTI para ajustar os parâmetros ventilatórios do paciente. Durante o procedimento, nota que o seu braço fora sujo por respingos de sangue do paciente; não fazia uso de óculos ou capa de proteção. Após garantir que o procedimento fora realizado e que o paciente estava bem ajustado no respirador, sai e dirige-se à pesquisadora e mostra-lhe o braço sujo. (CENA 1/ FISIOTERAPEUTA “D”)

\section{O trabalho prescrito}

A estrutura organizacional do HU foi reformulada no ano de 2007, com substituição das estruturas hierárquicas verticais, por um modelo circular/transversal. No modelo de gestão organizacional circular, não se eliminam as hierarquias, mas adota-se como meta mudar o centro das atenções da instituição para os usuários e assim facilitar a comunicação dentro da instituição. (HUPES, 2009)

A carga horária de trabalho dos fisioterapeutas assistenciais da UTI é de 120 horas mensais (30 horas semanais). Os dias de trabalho 
são prefixados com plantões ininterruptos de 24 horas na UTI e complementação da carga horária de 6 horas nas Unidades de Internação (UIs). Os fisioterapeutas mais antigos do serviço e concursados pela universidade têm prioridade para escolha dos plantões.

O quantitativo de pacientes é dividido entre os dois fisioterapeutas assistentes e o estagiário de fisioterapia. O coordenador de fisioterapia da UTI, eventualmente, no período da manhã, participa da assistência aos pacientes e da supervisão aos cursistas durante os atendimentos, quando ocorre remanejamento de um dos fisioterapeutas assistenciais da UTI, por carência em outras unidades do hospital.

Funcionam duas atividades docentes de fisioterapia na UTI, quais sejam: um estágio supervisionado vinculado a duas faculdades de Salvador e um curso de extensão vinculado à universidade. $\mathrm{O}$ curso não ocorre durante o período noturno, conforme negociação entre os fisioterapeutas e os gestores, uma vez que, segundo os fisioterapeutas, acompanhar o cursista durante as 24 horas gera uma demanda extra de trabalho.

O quantitativo e tempo de atendimento na UTI são bastante variáveis e são baseados no quadro clínico dos pacientes. Desta forma, enquanto alguns pacientes podem ser atendidos apenas uma vez por turno de seis horas, o que totalizaria dez atendimentos no período, outros podem necessitar de vários atendimentos.

Outras tarefas que competem ao fisioterapeuta na UTI são: a montagem, instituição, troca de filtros de respiradores, monitorização e assistência ventilatória aos pacientes sob ventilação mecânica; troca de frascos de aspiração e seus circuitos, após o uso; instalação de nebulizações em pacientes sob ventilação mecânica; registro de materiais sujos de fisioterapia para encaminhamento ao Centro de Esterilização de Materiais (CME); instituição e assistência ventilatória aos pacientes durante realização de exames externos à UTI, dentro da instituição.

Cabe, além disso, ao fisioterapeuta a realização das seguintes tarefas nas UIs: assistência fisioterapêutica a pacientes procedentes da UTI, que ainda necessitem de assistência noturna ou intensiva; transporte, montagem de respirador e ajuste de parâmetros ventilatórios a pacientes que necessitem de ventilação mecânica, enquanto não houver vagas nas UTIs, no período noturno ou em emergências. 
O controle de desempenho individual é realizado de acordo com o vínculo institucional. Para os servidores da universidade, é realizado a cada 18 meses, através da avaliação formal dos seguintes critérios: adaptabilidade; alcance de resultados; atendimento ao público; capacidade de solução de problemas; compromisso ético; compromisso com as funções, responsabilidades e metas; domínio das ferramentas de trabalho; interesse em capacitar-se profissionalmente; qualidade no trabalho; relacionamento interpessoal; trabalho em equipe e utilização racional dos recursos. Esta avaliação constitui-se um dos critérios utilizados para progressão do servidor na carreira pública.

Para os servidores de Secretaria de Estado que estão em fase de estágio probatório, é aplicada uma avaliação formal a cada seis meses. Os seguintes itens são ponderados: assiduidade; disciplina; iniciativa; produtividade e responsabilidade. A avaliação é realizada pela chefia imediata, justapondo-se a uma autoavaliação, sendo que o resultado pode variar de insatisfatório a excelente. Para os funcionários da Fundação de Apoio à Pesquisa não existe uma avaliação formal e esta é feita de forma subjetiva, de acordo com a necessidade que é determinada pela chefia imediata e pelo coordenador da UTI.

\section{A forma de gestão de riscos}

A realização de tarefas dentro da UTI está subordinada a normas de biossegurança que padronizam critérios a serem seguidos pelos trabalhadores que atuam naquele ambiente. Pressupõe-se, assim, que o modelo de segurança adotado na UTI baseia-se na forma tradicional que corresponde à prescrição de procedimentos e comportamentos seguros.

É importante citar que a legislação que dispõe sobre a Política Nacional de Biossegurança no Brasil está vinculada à Lei $\mathrm{n}^{\circ} 11.105$, de 25 de março de 2005. A Portaria $\mathrm{n}^{\circ} 37$, de 6 de dezembro de 2002, instituiu a Norma Regulamentadora (NR) 32, que trata especificamente da segurança e saúde do trabalho nos estabelecimentos de assistência à saúde.

Na UTI, encontra-se disponível o "Manual de Infecção Hospitalar", que foi elaborado pelo SCIH e discorre sobre as precauções básicas que dizem respeito a medidas que devem ser adotadas pelos trabalhadores de saúde, quando em contato com sangue e fluidos corpóreos, de 
qualquer paciente considerado como potencialmente infeccioso para o vírus HIV, Hepatites $\mathrm{B}$ e $\mathrm{C}$ e de outros patógenos sanguíneos. Essas medidas incluem a utilização de EPI e/ou Equipamentos de Proteção Coletiva (EPC). (BRASIL, 1983)

No tocante ao fornecimento dos EPIs, conforme se observa na fala dos fisioterapeutas, esses materiais nem sempre são de boa qualidade, o que gera insegurança para eles, como verbaliza um dos fisioterapeutas: "Aqui todas são muito finas" [refere-se à capa descartável]. "Essas luvas são de péssima qualidade, são extremamente porosas [...]. Essa daqui não cabe nem $1 \mathrm{~L}$ de água, se colocar $2 \mathrm{~L}$, ela nem vai, ela estoura" [refere-se ao teste de vazamento da luva sugerido pelo SCIH que consiste em colocar 2L de água dentro da luva e observar vazamentos; se ocorrerem é porque é de qualidade duvidosa] (FISIOTERAPEUTA "F").

Observa-se a culpabilidade do trabalhador implícita no fluxograma (disponível na UTI) a ser seguido pelos trabalhadores em caso de acidentes com sangue e fluído biológico, quando em contato com mucosas, ou acidentes perfurocortantes. Neste fluxograma estão contidas importantes informações das etapas a serem seguidas após o acidente, contudo evidencia-se em uma das etapas o encaminhamento do profissional acidentado para treinamento. Este encaminhamento pode estar baseado na concepção sobre acidente de trabalho (AT) e sua causalidade que admite ser o AT acarretado apenas por imperícia do trabalhador. Neste caso, o contexto no qual o acidente foi gerado e as condições reais encontradas durante o cumprimento das tarefas são negligenciadas.

\section{O trabalho real}

As circunstâncias em que o trabalhador se encontra para executar suas tarefas diferem das condições determinadas a priori, observando -se que, muitas vezes, entram em choque com as tentativas de padronização, haja vista os processos organizacionais e a estrutura existente.

\section{Relações entre as equipes}

A UTI, por ser um local de circulação mais restrita de pessoas, permite um convívio mais próximo entre as equipes de trabalhadores que ali atuam. Em geral, o relacionamento observado é afetivo e cordial. 
As equipes conversam durante os plantões de forma amigável, interagem entre si nos horários que conseguem tirar alguma folga.

No desenvolvimento das tarefas, observa-se complementaridade e interdependência das diferentes categorias profissionais. Podem-se mencionar como exemplos situações em que a equipe de enfermagem realiza transferências de pacientes do leito para macas com o auxílio de fisioterapeutas e médicos. Outra situação seria quando a equipe de fisioterapia coloca o paciente para deambular ou faz transferência deste do leito para cadeira, com o auxílio da equipe de enfermagem no manuseio de soluções e medicamentos em uso.

Todavia, nesta complexa trama de saberes, cuidados e interações sociais, ocorrem situações de conflitos e até de disputa entre esses trabalhadores. Podem-se citar situações conflitantes entre as equipes de fisioterapia e enfermagem, no que se refere à aspiração dos pacientes. Observam-se atitudes de relutância das equipes em relação ao que lhes cabe como tarefa. Podem-se trazer à baila situações em que o fisioterapeuta é interrompido durante a realização de atendimento a um paciente para que realize exclusivamente aspiração de secreção respiratória em outro paciente, como se evidencia na fala seguinte:

A equipe de enfermagem não aspira o paciente. Eventualmente acontece,
elas fazem depois do banho, mas a maioria não faz, tanto é que elas dão ba-
nho na paciente, depois elas mandam chamar a gente dizendo que o paciente
está desconfortável. A gente sabe que é secreção. Teoricamente, se elas estão
dando banho no paciente, fazer uma aspiração no paciente que está descon-
fortável, não deixa de ser uma higiene, então elas podem aspirar, porque não
é coisa só da gente. [...] A gente não tem como ficar aspirando. Imagine que
aqui tem 10 pacientes, se toda hora a gente ficar indo no leito do paciente
pra realizar uma aspiração que a equipe de enfermagem poderia ter feito, a
gente deixa de dar atendimento a outro paciente. Se a gente tiver que aspirar
mais 3, 4 vezes cada paciente, são 10 [refere-se ao quantitativo de pacientes].
(FISIOTERAPEUTA "D")

A cena demonstra que a indefinição do que cabe como tarefa aos profissionais pode ser objeto de conflito entre os membros das equipes de fisioterapia e de enfermagem. Em um estudo qualitativo realizado por Nascimento e colaboradores (2006), referente à profissionalização da fisioterapia, nas décadas de 50 a 80 em Minas Gerais, os autores ressaltam que a definição e o desenvolvimento das competências do fisioterapeuta nas equipes de saúde foram motivo de disputa e conflitos 
entre os profissionais de enfermagem e de fisioterapia, sendo que as atividades passaram a ser desenvolvidas e estruturadas de acordo com sua complexidade, ficando estabelecido que as atividades consideradas de menor complexidade começaram a ser delegadas aos auxiliares de enfermagem e as de maior complexidade foram incorporadas pelos fisioterapeutas.

De acordo com Farrell, Schimiti e Heinemann (2001), na convivência multiprofissional, as equipes muitas vezes podem se tornar polarizadas na luta pelo poder entre subgrupos, com diferentes visões sobre como estes devem funcionar. À medida que os membros convivem, descobrem as divergências sobre sua missão, como o trabalho deve ser organizado e as formas de controle de determinados grupos sobre os outros.

Considerando que a profissão de fisioterapeuta teve sua autonomia profissional reconhecida, a partir do Decreto Lei no 938 de 13 de outubro de 1969, portanto há apenas 41 anos, e que não há no Código de Ética desta categoria o que lhe cabe como tarefa, é esperado que sua autonomia e suas competências sejam desenvolvidas dentro de visões, muitas vezes, inconciliáveis, de distintos atores, a partir dos diferentes espaços que ocupam numa mesma instituição. (CECÍLIO, 2005)

Outra situação que expressa esta tensão ocorre quando os fisioterapeutas, durante a realização de atividades assistenciais aos pacientes, são surpreendidos pela equipe de enfermagem que inicia os banhos e até curativos antes que os fisioterapeutas finalizem as suas tarefas. Isso força o fisioterapeuta a acelerar a execução de um procedimento que já está em curso e interromper outras condutas que realizaria naquele momento, fragmentando assim suas atividades. A cena descrita a seguir pode evidenciar esta experiência.

O fisioterapeuta está no isolamento respiratório, em uso de capa, máscara de barreira, luvas, aspirando um paciente e, durante suas condutas, um técnico de enfermagem entra no quarto e o avisa que terá de iniciar o banho, pois o plantão está pesado e ele está atrasado. O fisioterapeuta argumenta que está no meio de um procedimento, mas cede. Quando sai do quarto, comenta com a pesquisadora: “[...] preferi não contestar muito, pois não conheço bem este técnico e não quero causar atritos entre as equipes de fisioterapia e enfermagem, que têm um bom relacionamento [...]". O fisioterapeuta interrompe a sua atividade, reti- 
ra todos os EPIs e sai do quarto, dirigindo-se para outro leito. (CENA 2/ FISIOTERAPEUTA “O”)

$\mathrm{Na}$ análise dessa cena, evidencia-se que, embora o fisioterapeuta, no seu discurso expresse que tem um bom relacionamento com a equipe de enfermagem, em vários momentos percebe-se o desrespeito e o não reconhecimento da importância do trabalho do fisioterapeuta, com prejuízo na sua autonomia nesta unidade.

Naronem e Wikstrom-Grotell (1999) salientam que a autonomia do profissional pode estar comprometida se não houver uma clara definição da especificidade da fisioterapia e apropriação por parte do fisioterapeuta do seu espaço nas equipes de saúde. Nascimento e colaboradores (2006), de forma semelhante, consideram que para afirmação efetiva do fisioterapeuta se faz necessário o estabelecimento da competência (seu saber e fazer) como instrumento de sua apropriação e atuação, o que denota ser capaz de delimitar seu papel na equipe interdisciplinar.

\section{O rápido aumento da demanda de trabalho ou demandas conflitantes}

No ambiente da UTI, são constantes as intercorrências com os pacientes, o que consiste em situações clínicas de emergência, fazendo com que toda a equipe se mobilize rapidamente. Isto gera célere intensificação da demanda de trabalho e aumento das restrições de tempo. De acordo com Guérin e colaboradores (2001), a intensificação do trabalho refere-se ao uso das capacidades cognitivas e fisiológicas dos trabalhadores, que a depender das escolhas de soluções e dos compromissos firmados, podem ultrapassar seus limites e contribuir para sua exposição aos riscos e consequente degradação da sua saúde.

Pode-se observar que o tempo é um dos elementos mais importantes na determinação dos modos operatórios dos fisioterapeutas. A complexidade do atendimento e a demanda de pacientes impõem ao fisioterapeuta o desenvolvimento de habilidades para que essas restrições sejam superadas, ainda que essas ocasionem agravos à saúde. Além disso, esses profissionais estão submetidos a protocolos de operacionalização de suas tarefas e necessitam de margem de tempo e de 
liberdade durante o seu trabalho para operacionalizar as suas atividades dentro das situações reais que se apresentam no seu cotidiano.

A fala de um Fisioterapeuta evidencia o que se diz:

O ritmo da UTI é muito intenso. Paciente de UTI já é um paciente que precisa de um cuidado maior, mas os pacientes daqui precisam de um cuidado maior ainda, porque são pacientes que já chegam bem debilitados ou vêm acumulando ao longo do tempo algum problema, doença por cima de doença. Ele termina chegando aqui bem gravizinho, já bem difícil de cuidar, então a gente já sai cansado por conta disso. São pacientes que a gente tem que trabalhar bastante. A gente tem um protocolo a ser seguido, então a gente tem que fazer, trabalhar a parte ventilatória toda do paciente [...]. (FISIOTERAPEUTA “D”)

Nas ocasiões de maior demanda, o risco de acidentes aumenta consideravelmente. A dificuldade é saber como conciliar rapidez e atenção, com cuidado na execução da tarefa em situações de emergência, em que a prioridade é restabelecer as condições clínicas do paciente. Isso é caracterizado pela cena descrita abaixo: A fisioterapeuta está orientando um cursista para higienizar um oxímetro que transferirá de um paciente para outro; ao olhar para o monitor observa e comenta: "paciente parou"; corre e ajuda nas manobras de cardiorressuscitação da paciente "A". Após reversão da situação, vai participar da ventilação da paciente "B", que será submetida a uma cardioversão elétrica; para isso, adapta uma luva de procedimentos como, reservatório de oxigênio na bolsa valva e começa a ventilar a paciente. Neste momento, há 11 pessoas ao lado da paciente. A fisioterapeuta então é chamada para uma nova urgência, pois o paciente "C" está com grande esforço respiratório. Transfere a ventilação do " $\mathrm{B}$ " para um dos médicos residentes e se dirige rapidamente ao paciente "C". Após exame, começa a aspirar e ajusta o respirador. Constatado que o paciente " $\mathrm{D}$ " está "dessaturando" e ventilando mal, a fisioterapeuta mais uma vez é solicitada, então avalia, aspira, ajusta o respirador. Retorna para a paciente "B" para ajudar e então comenta: "fisioterapeuta não consegue nem tomar remédio". Mais uma vez é chamada, pois o paciente "B' que fez vários períodos de bradicardia agora está com muita secreção pulmonar e "dessaturando". Sai correndo, começa a aspirar sem máscara. No decorrer da aspiração pega a máscara que se encontrava próximo ao seu rosto e a ajusta de qual- 
quer maneira, então cogita: "é muita aspiração em tão pouco tempo". (CENA 3/ FISIOTERAPEUTA “D”)

Como se pode observar, são quatro pacientes que, simultaneamente, apresentaram intercorrências clínicas com súbito aumento da demanda de trabalho para o fisioterapeuta. Assim, a pressão de tempo determina a maior vulnerabilidade do trabalhador ao contato com fluidos corpóreos dos pacientes com a sua pele e as suas mucosas.

Os fisioterapeutas experimentam constantes interrupções em suas rotinas de trabalho, decorrentes das emergências e das diversas contingências ocorridas com grande frequência na UTI ou em outras unidades. A cena abaixo evidencia uma dessas situações:

O fisioterapeuta é interrompido durante as suas condutas e é solicitado a atender a um telefonema procedente da UI. Observa-se que durante o telefonema se mostra irritado com o conteúdo da conversa e comenta: "coleta é só aspirar e colocar no copo". Após desligar o telefone, diz: "ela [refere-se à enfermeira de uma Unidade de Internamento] quer que eu vá lá fazer uma cultura do paciente. Qualquer profissional pode fazer isso. Ligar para aqui e eu ter que ir lá embaixo, fazer uma aspiração do paciente! Aí é demais". (CENA 4/ FISIOTERAPEUTA “D”)

Pode-se perceber, desta forma, que o fisioterapeuta não tem alto grau de controle sobre o trabalho no qual está inserido, embora sua capacidade de regulação seja fundamental para que ele possa gerir as variabilidades. Segundo Abrahão (2000, p. 51),

[...] quanto maior a variabilidade das situações, menor a probabilidade de antecipação, exigindo assim, maior competência dos trabalhadores para a passagem de uma operação prescrita a uma ação situada (contextualizada). Esta competência possibilita, também, redefinir a atividade, favorecendo a reconstituição de situações anteriores por meio de reformulações, utilizando para isto recursos do próprio contexto como, por exemplo, o apelo à competência de outros trabalhadores, a elaboração de novos parâmetros para esta atividade ou, até mesmo, a utilização eventual de uma estratégia operatória antiga.

\section{As estratégias utilizadas diante das limitações de materiais}

$\mathrm{Na}$ UTI, os fisioterapeutas, muitas vezes, encontram limitadas condições materiais e inadequação de equipamentos. Tais limitações levam esses sujeitos a desenvolverem estratégias operatórias - depen- 
dentes das experiências adquiridas durante a sua vida profissional, no relacionamento com o outro - para gerirem as variações internas e externas, minimizando assim os riscos biológicos ao desenvolverem o seu trabalho.

Para Barros e colaboradores (2006), por meio de um estudo realizado em um Pronto-Socorro de um Hospital, ficaram evidentes a criação de vínculos e as negociações cotidianas entre os trabalhadores para que a efetuação do trabalho fosse possível e tivesse melhor qualidade. Tal posicionamento demonstrou o desenvolvimento de estratégias para lidar com a alta imprevisibilidade do trabalho.

Segundo Guérin e colaboradores (2001), as atividades de um operador em um determinado momento são organizadas em função de diferentes objetivos e, a depender da situação, a margem de manobra que este tem para atender a tais objetivos pode ser maior ou menor.

Outra situação observada diz respeito à falta de materiais privativos nos leitos dos pacientes sob isolamento de contato. No Manual de Infecções Hospitalar da SCIH do Hospital, consta que nos leitos em isolamento de contato deve haver preferencialmente um estetoscópio disponível para uso exclusivo. Contudo, vê-se a cena descrita adiante: ao entrar no quarto e pegar o estetoscópio de uso privativo do paciente, o fisioterapeuta percebe que o mesmo encontra-se com defeito, sem uma das olivas, e o diafragma solta com facilidade. Então, avisa à cursista que esta deve pegar três luvas, sendo que uma das luvas deverá ser utilizada sobre o diafragma do seu estetoscópio para protegê-lo. O fisioterapeuta justifica que optou por colocar a luva por se tratar de uma proteção a mais, para que, ao transportar o seu estetoscópio junto com seus pertences pessoais em sua mochila e posteriormente usá-lo em outros pacientes, a cursista não corresse o risco de contaminação. Em seguida, faz a seguinte verbalização para a pesquisadora:

No caso desse leito, que não tem disponível estetoscópio pra gente fazer a avaliação [...], temos que usar o nosso estetoscópio, que é uma coisa que não gosto de fazer, particularmente, mas com a limitação que a gente tem no hospital, a gente não tem outra opção. (CENA 5/FISIOTERAPEUTA “H”)

Percebe-se que, ao usar uma luva amarrada sobre o diafragma do estetoscópio durante a ausculta dos pulmões do paciente, o fisioterapeuta faz uso de uma regulação para assim supostamente prevenir a 
contaminação de seu estetoscópio, minimizando os riscos de transmitir infecção para outros pacientes e para ele mesmo. Assim, à medida que o conhecimento tácito do fisioterapeuta vai se consolidando, o mesmo vai lançando mão de estratégias para vencer as adversidades no contexto da UTI.

De acordo com Abrahão (2000), no trabalho real existem situações em que não é suficiente para o trabalhador apenas cumprir regras, é necessário interpretar, corrigir e, muitas vezes criar, para atender às exigências da situação de trabalho.

Outra situação observada ocorreu durante a realização de aspirações de secreções pulmonares nos pacientes internados na UTI. Note-se na cena descrita abaixo:

Durante a aspiração de um paciente, a cursista chama o fisioterapeuta e comenta: "o vácuo não está pegando nada, o vácuo não está funcionando". O fisioterapeuta, então, faz ajustes na conexão do frasco de aspiração com o vácuo e com a válvula de controle de força do vácuo e então pergunta: "Está funcionando, não está? Pela zoada acho que está [...]. Quem aguenta?” Posteriormente, comenta que demorou muito nos atendimentos na noite anterior por conta de o vácuo de aspiração estar com problemas e completa: "a sorte é que os outros estavam tranquilos, não requereram muita atenção" [refere-se aos demais pacientes da UTI]. (CENA 6/ FISIOTERAPEUTA “B”)

$\mathrm{Na}$ cena descrita, observa-se que o trabalhador usou sua competência, mobilizando sua subjetividade e desenvolvendo uma atitude que permitisse uma antecipação dos eventos, para assim realizar o seu trabalho. Esta ação foi compartilhada pelo (a) cursista.

Em uma das cenas, os fisioterapeutas usam como estratégia o racionamento de capa descartável para evitar falta desse dispositivo de proteção: Um fisioterapeuta está pronto para colocar uma paciente na posição sentada e chama seu colega para auxiliar: "vamos aqui, que esta paciente é muito pesada". O colega então responde: "não, vamos economizar a capa, né?”. Neste dia, a UTI está com sete pacientes sob isolamento de contato e para atender a esses se faz necessário o uso de capas descartáveis de proteção (CENA 7/FISIOTERAPEUTAS “S” e "D").

Segundo Guérin e colaboradores (2001), os responsáveis pela organização do trabalho frequentemente minimizam a variabilidade do trabalho, dos sistemas técnicos, da diversidade dos serviços a realizar, 
ou dão a impressão de que essa variabilidade é totalmente previsível e controlável; contudo, é no exercício vivo de suas funções que os trabalhadores vão passar por momentos em que só o seu trabalho permite a regulação desses incidentes, e isto não é simples.

A despeito dos riscos de contato com material biológico nos olhos durante suas tarefas, principalmente aspirações de secreções pulmonares, os fisioterapeutas as realizam sem uso de óculos de proteção. Constatemos nas cenas e falas abaixo demonstradas:

O fisioterapeuta realiza, juntamente com a cursista, manobras de tosse assistida, pressurizações com o respirador e aspirações de secreções em um paciente tetraplégico que tem dificuldade de eliminar secreções. Durante as condutas, o paciente não só apresenta grande volume de secreção purulenta como também apresenta intercorrências, sangramento de vias aéreas superiores importantes. Para realização das condutas, observa-se que o fisioterapeuta não faz uso de máscara ou óculos de proteção. Após conseguir estabilizar a situação clínica do paciente, através de ações conjuntas com a equipe, e quando se dirige para a higienização das mãos, relata sobre o não uso dos EPIs: "estresse, estresse puro". (CENA 8/ FISIOTERAPEUTA “Q”)

Mas é porque aqueles óculos realmente atrapalham muito. Eu não enxergo nada com aquilo, porque fica embaçando, então eu não consigo enxergar. Aquilo então fica me agoniando porque não estou enxergando e acabo fazendo sem [...]. Não acopla direito [...]. (FISIOTERAPEUTA “B”)

Eu geralmente não uso óculos, porque incomoda muito, embaça e eu não consigo enxergar nada mesmo. Só uso quando é uma bactéria que ainda não se sabe muito os mecanismos de contaminação, quando ainda não está esclarecido [...]. (FISIOTERAPEUTA “P”)

De acordo com Porto (2007), o trabalhador, pela maior exposição devido ao uso incorreto de EPIs pode, de vítima, ser perversamente transformado em culpado pelos gestores, através da atribuição de conceitos, como a classificação de ato inseguro, por exemplo. Contudo, esta avaliação mostra-se preconceituosa e descontextualizada da realidade cotidiana vivida por estes trabalhadores. As falas e cenas descritas demonstram que o uso dos EPIs, na maioria das vezes, não só gerou grande desconforto aos trabalhadores, impossibilitando a realização da sua tarefa, como também ficou impraticável devido às contingências 
apresentadas. Muitas vezes, o desconforto no uso do EPI decorre de sua inadequação ao uso e baixa qualidade que inviabiliza ao trabalhador executar sua tarefa. Neste caso, ele faz a opção de realizar a tarefa sem se proteger. Conforme afirma Guérin e colaboradores (2001), o primeiro compromisso do trabalhador é com a conclusão da tarefa. Ou seja, os trabalhadores agem diante das condições encontradas, muitas vezes tendo que se afastar da regra, do comportamento que na norma seria seguro, para assim cumprir as suas tarefas. (HORLIK- JONES, 2008)

\section{O saber de prudência: as estratégias invisíveis de proteção}

São várias as racionalidades práticas desenvolvidas pelos fisioterapeutas diante dos riscos biológicos observadas no cotidiano desta UTI. Isto pode ser desvelado na cena e fala abaixo:

Ao aspirar os pacientes, o fisioterapeuta sempre se posicionava por trás da cabeceira destes, fora da direção das secreções respiratórias que poderiam ser expelidas quando o paciente tossisse. Posteriormente, na autoconfrontação, o mesmo explica: "Eu, quando estou sem óculos, me protejo, procuro ficar por trás da cabeceira do paciente para evitar que a secreção pegue em mim". (CENA 9/ FISIOTERAPEUTA “B”)

Segundo Amalberti (1996) apud Diniz, Assunção e Lima (2005), o trabalhador age mobilizando os seus recursos cognitivos para avaliar a situação; avalia, por isso, a possibilidade de risco no procedimento em curso, verificando o nível de exigência e os resultados esperados e assim elabora uma ação apropriada.

A cena abaixo demonstra uma dessas situações:

Em um plantão, o fisioterapeuta começou a trocar os filtros que são colocados entre a via aérea artificial dos pacientes e os tubos corrugados dos respiradores. Estes filtros encontram-se, quase sempre, com secreções respiratórias em seu interior. Em todas as trocas o (a) Fisioterapeuta sempre procedia da seguinte forma: primeiro desconectava o tubo do filtro, virava este tubo contrário à sua direção e aí então trocava o filtro. Ao ser convidado a verbalizar, afirmou: "sempre que tem secreção eu só abro aqui para evitar que venha no meu rosto". (CENA 10/ FISIOTERAPEUTA “B”) 
Observou-se também que todas as vezes que os fisioterapeutas aspiravam secreções respiratórias dos pacientes, esses só fechavam o vácuo de aspiração após acabarem todo o procedimento e colocarem a borracha de silicone pendurada sobre o frasco de aspiração. Esta é uma forma de proteção utilizada por esses sujeitos, visto que, assim, evitam que as secreções que tenham ficado no silicone após o procedimento retornem, ao elevarem o silicone para enrolar sobre o frasco e venham a ter contato com sua pele ou mucosa.

Outro procedimento que revela o saber de prudência dos fisioterapeutas é a utilização de duas luvas ao aspirar as secreções respiratórias dos pacientes; verificou-se, em dada ocorrência, que esses profissionais usavam uma luva estéril por cima da luva de procedimento. Em outras ocasiões, percebe-se que esta é uma estratégia de proteção por não confiar na qualidade das luvas.

A cena seguinte demonstra outra estratégia: Ao entrar nos isolamentos de contato e vestir a capa de proteção, observa-se que o fisioterapeuta faz um furo em cada manga, próximo ao punho, e através deste introduz o seu polegar. Posteriormente calça as luvas de procedimentos, as quais envolvem o punho por cima da capa. Assim, impede que a manga se desloque para cima e o seu punho fique descoberto durante as aspirações de secreções. (CENA 11/ FISIOTERAPEUTA “C”)

Garfinkel (2006) convenciona que o mundo do ator social no seu trabalho não é objeto do seu pensamento, mas é um campo particular onde ele vai agir como um intérprete crítico, sob condições específicas. Assim sendo, podemos inferir que o ator social no seu trabalho vai desempenhar o seu papel baseado em um universo de elementos peculiares que para ele é reconhecido como: real, relevante e significante; desse modo, ele vai interpretar esse universo abalizado no seu contexto específico.

\section{O acúmulo de funções do fisioterapeuta}

Além de realizar as atividades de fisioterapia motora e respiratória na UTI, o fisioterapeuta participa do transporte de pacientes sob ventilação mecânica ao Setor de Bioimagem do Hospital. Além disso, responsabiliza-se por retirar o respirador do paciente na UTI, transportar o aparelho até o Setor de Bioimagem, reinstituir a ventilação no paciente 
e promover assistência ventilatória durante a realização do exame, o que inclui ajustes necessários no respirador.

Assim, uma das estratégias utilizadas por esse sujeito é permanecer no local durante o exame, o que evita repetidos retornos ao setor quando surge qualquer problema no respirador. Evidencia o fato a fala de um dos fisioterapeutas da cena descrita abaixo: "Prefiro ficar no local durante toda a realização do exame, pois assim evito que ao retornar para a UTI seja chamado para fazer novos ajustes na ventilação mecânica, por alguma alteração clínica no paciente". (CENA 12/ FISIOTERAPEUTA “G”)

O fisioterapeuta enfrenta também outras restrições durante a participação no transporte de pacientes, pois os elevadores disponíveis no Hospital possuem muitos problemas. Podem-se mencionar: pequeno espaço interno, o que faz com que a equipe se divida em dois elevadores; demora a chegar ao piso solicitado, devido ao número reduzido de elevadores e quebras constantes.

Tais contingências consomem grande parte do tempo disponível do fisioterapeuta para realizar as suas tarefas assistenciais na UTI, o que o faz compensar esse tempo com a aceleração de suas atividades para cumprir as metas estabelecidas.

Outra tarefa que compete aos fisioterapeutas da UTI é o atendimento de intercorrências clínicas nas unidades de internamento, no período das 19 às 7h, e não raramente em outros horários em que não se consegue contatar o fisioterapeuta da unidade. Muitas vezes, o fisioterapeuta, depois de instituir a ventilação, prefere aguardar o primeiro resultado da gasometria, que se faz necessário para adequação ventilatória, sabendo que ao chegar à UTI será imediatamente chamado para ajustar parâmetros, o que demandará maior tempo e deslocamento. Todos estes desvios de função provocam interferências no trabalho do fisioterapeuta ao retornar para UTI, impondo-lhe restrição de tempo.

Igualmente, outra função prescrita aos fisioterapeutas da UTI é a realização de atendimentos nas unidades de internamento em pacientes que necessitam de assistência fisioterapêutica noturna, o que faz com que esses se desloquem para as unidades com frequência. As múltiplas funções às quais o fisioterapeuta é submetido durante o seu plantão geram aumento de carga de trabalho. 


\section{Considerações finais}

A caracterização das tarefas no contexto de trabalho de uma UTI, através do uso de elementos da Etnometodologia e da AET, possibilitou, por meio da análise das ações dos fisioterapeutas, a identificação das variabilidades do trabalho, evidenciando como são geradas as demandas extraordinárias e como os trabalhadores agem diante das inadequações dos meios de trabalho associadas aos riscos biológicos presentes no seu cotidiano. Constatou-se, portanto, como reagem esses profissionais em um ambiente tão complexo como a UTI, onde ocorrem transformações da situação de trabalho em ínfimos interstícios, nas chamadas urgências e emergências, em que se faz necessário o contato direto ao assistir o paciente grave.

A análise do trabalho permitiu desvelar que o fisioterapeuta na UTI, ao realizar o trabalho real, lança mão de suas competências para regular e assim gerir estratégias a fim de minimizar os riscos de contaminação com material biológico e mitigar a inadequação dos recursos materiais na realização das suas atividades.

Evidenciaram-se os múltiplos tipos de vínculos de trabalho dos fisioterapeutas na UTI, que podem gerar diferentes formas de gestão do trabalho, gestão de pessoal e repercussões sobre a saúde do trabalhador. Há entre eles, os fisioterapeutas concursados, servidores da Universidade, mas há os terceirizados. Sabe-se que o processo de terceirização tem sido identificado com o aumento de insegurança dos trabalhadores, porquanto a responsabilidade de garantir a saúde e a segurança é, geralmente, transferida para terceiros. Além disso, foi possível constatar o acúmulo de vínculos de trabalho dos fisioterapeutas com outras instituições, o que pode refletir os baixos salários, demandando, o acúmulo de vários empregos. Com isso, alguns atingem carga horária mensal de até 360 horas de serviço.

Embora o fisioterapeuta, no seu discurso, expresse que as relações interpessoais na UTI sejam satisfatórias, evidenciou-se que no cotidiano do trabalho, em que se exercem múltiplos saberes, cuidados e interações sociais, ocorrem situações de conflitos e até de disputa entre os trabalhadores, em particular entre fisioterapeutas e equipe de enfermagem. Parece que a indefinição do que cabe como tarefa aos profissionais pode ser objeto de conflito, mas não se pode omitir que sendo 
a fisioterapia uma profissão de mais recente regulamentação, a afirmação efetiva do fisioterapeuta requer a consolidação da sua competência (seu saber e fazer), como instrumento de sua apropriação e atuação, a fim de delimitar seu papel na equipe interdisciplinar.

O controle de riscos na UTI está baseado na elaboração de regras e em manuais operacionais para diversas situações, que têm como objetivo, supostamente, proteger os profissionais na execução do seu trabalho. Contudo, esta concepção de segurança, que corresponde à prescrição de procedimentos e comportamentos seguros, admite que o dano à saúde dos trabalhadores ou o acidente de trabalho, em particular, decorre da imperícia do trabalhador, negligenciando, nesta perspectiva de análise, o contexto no qual o acidente foi gerado e as condições reais encontradas durante o cumprimento das tarefas. No trabalho real, existem situações em que não é suficiente para o trabalhador apenas cumprir regras, é necessário interpretar, corrigir e, muitas vezes criar, para atender às exigências da situação de trabalho.

O estudo revelou a centralidade da variável tempo na definição da carga de trabalho para os fisioterapeutas. Trata-se de um dos elementos mais importantes na determinação dos modos operatórios dos fisioterapeutas, quando a dificuldade é saber como conciliar rapidez e atenção, com cuidado na execução da tarefa em situações de emergência, em que a prioridade é restabelecer as condições clínicas do paciente. A pressão de tempo determina a maior vulnerabilidade do trabalhador no contato com fluidos corpóreos dos pacientes com a sua pele e as suas mucosas.

Os fisioterapeutas experimentam constantes interrupções em suas rotinas de trabalho, decorrentes das emergências e das diversas contingências ocorridas com grande frequência na UTI, evidenciando-se a existência de demandas conflitantes em um contexto de limitadas condições materiais e inadequação de equipamentos. Tais limitações levam esses sujeitos a desenvolverem estratégias operatórias, dependentes das experiências adquiridas durante a sua vida profissional, para gerirem as variações internas e externas, mobilizando sua subjetividade e desenvolvendo uma atitude que permita a antecipação de eventos, com o fim de assegurar o cumprimento das tarefas e minimizar os riscos biológicos, com o seu saber de prudência.

Ao gerar regulações para contornar as perturbações no seu trabalho, o fisioterapeuta age como um decodificador das regras diante da 
situação concreta do seu cotidiano, do seu espaço de atuação, delimitando o que é real e, assim, estabelece metas e compromissos de qualidade e produção. Por isso, não pode ser julgado com um descumpridor de normas e rotinas ou como um ser que está naturalizando o risco no seu cotidiano, mas como um ser inteligente capaz de regular perturbações com compromisso e qualidade, ainda que, muitas vezes, em detrimento da sua própria saúde.

Este estudo traz elementos para se compreender, em outros contextos, como os fisioterapeutas realizam suas ações práticas diante da insuficiência dos meios, e dos riscos biológicos, visando a atender as exigências do trabalho.

\section{Referências}

ABRAHÃO, Júlia Issy. Reestruturação Produtiva e Variabilidade do Trabalho: Uma Abordagem da Ergonomia. Psicologia: Teoria e Pesquisa, n. 16, p. 49-54, jan.- abr. 2000.

BARALDI, Solange et al. Globalização e seus Impactos na Vulnerabilidade e Flexibilização das Relações de Trabalho em Saúde. Trabalho Educação e Saúde, n. 6, p. 539-548, nov. 2008/2009.

BARBOSA, Anadergh. Riscos ocupacionais em hospitais: um desafio aos profissionais da área de saúde ocupacional. 1989. 126 f. Dissertação (Mestrado em Medicina). Universidade Federal de Santa Catarina, Florianópolis, 1989.

BARROS, M. E. de B. et al. As Articulações Saúde e Trabalho: Relato de Experiência em um Hospital Público. Cadernos de Saúde Coletiva, Rio de Janeiro, n.14, p.451-468, set. 2006.

BORGES, A.; FRANCO, A. Mudanças de Gestão: Para Além dos Muros da Fábrica. In: FRANCO, Tânia (Org.). Trabalho Riscos Industriais e Meio Ambiente: Rumo ao Desenvolvimento Sustentável. EDUFBA: Salvador, 1997. 242 p.

BRASIL. Ministério da Saúde. Norma Regulamentadora - NR

6. Diário Oficial da União, Brasília - DF., 14 mar. 1983.

BULHÕES, I. Riscos do trabalho de enfermagem. 2. ed. Correio Carioca: Rio de Janeiro, 1998, 221 p.

CAIXETA, R. de B.; BARBOSA-BRANCO, A. Acidente de trabalho, com material biológico, em profissionais de saúde de hospitais 
públicos do Distrito Federal, Brasil, 2002/2003. Caderno de Saúde Pública, n. 21, p. 737-746, mai.- jun. 2005.

CECÍLIO, L. C. de O. É possível trabalhar o conflito como matériaprima da gestão em saúde? Cadernos de Saúde Pública, Rio de Janeiro, n. 21, p. 508-516, mar.- abr., 2005.

COULON, A. Etnometodologia. Vozes: Rio de Janeiro, 1995. 134 p.

DEAN, E. Oxygen transport: a physiologically-basead conceptual framework for the pratice of cardiopulmonary physiotherapy. Physiotherapy, n. 6, p. 347-355, jun. 1994.

DEAN, E.; ROSS, J. Discordance between cardiopulmonary physiology and physical therapy: toward a rotinal basis for practice. Chest, n. 6, p. 1694-1698, jun. 1992.

DINIZ, E. P. H.; ASSUNÇÃO, A.A.; LIMA, F. de P.A. Prevenção de acidentes: o reconhecimento das estratégias operatórias dos motociclistas profissionais com base para a negociação de acordo coletivo. Congresso brasileiro de Ergonomia, XII. Recife, 2005. Disponível em: <www. scielosp.org/scieloOrg/php/art.... >. Acesso em: 13 jul. 2009.

DRUCK, M. da G. Terceirização: (Des)fordizando a fábrica. EDUFBA: Salvador, 1999. 280 p.

ELY, E.W.; BAKER A.M.; DUNGAN D.P. Effect on the duration of mechanical ventilation of identifying patients capable breathing spontaneously. New Englad Journal Medicine, n. 335, p.1864-1865, Dec. 1996.

FARRELL, M. P.; SCHMITT, M.H; HEINEMANN, G.D. Informal Roles and the Stages of Interdisciplinary Team Development. Journal of Interprofessional Care, n. 3, p. 281-295, Aug., 2001.

GARFINKEL, H. Seeing Socilogically: the routine grounds of social action. Paradigm: Colorado, 2006. 239 p.

GASPAR, P.J.S. Enfermagem profissão de risco e de desgaste: perspective do enfermeiro de urgência. Nursing, n. 10, p. 23-24, 1997.

GUEDES, R. M. de A.; LIMA, F. de P. A.; ASSUNÇÃO, A. A. O programa de qualidade no setor hospitalar e as atividades reais de enfermagem: o caso da medicação. Ciências e Saúde Coletiva, n. 10, p. 63-76, out./dez. 2005.

GUÉRIN, F. et al. Compreender o Trabalho para Transformá-lo A Prática da Ergonomia. São Paulo: Edgard Blucher, 2001. 198 p.

GUTTENBERG, Y.V.; SPICKETT, J. A Survey of Occupational Exposure to blood and Body Fluids in Physiotherapists in Western Australia.

Asia- Pacific Journal of Public Health, n. 4, p. 508-519, Oct. 2009. 
HALL, J. B.; WOOD, L.D. Liberation of the patient from mecanical ventilation. Journal of the American Medical Association, n. 27, p. 621-1628, Marc., 1987.

HAVE, P.T. Understanding Qualitative Research and Ethnomethodology. London: SAGE, 2004. 196 p.

HORLIK-JONES, T. Risk, Praxis and Everyday Life. ISA World Forum of Sociology, Barcelona, set. 2008. Disponível em: <http://www.riskanduncertainty.net/Tom_HorlickJones.pdf > . Acesso em: 10 de outubro de 2008.

HORST, H. M. et al. Decrease in ventilation time with a standardized weaning process. Archives of Surgery, n. 133, p. 483-488, 1998.

HUPES - Hospital Universitário Professor Edgar Santos.

Material Institucional. Disponível em: < http:intranethupes. ufba.br.>. Acesso em: 01 dez. 2009.

LIMA, F. de P.A. de. Introdução à análise ergonômica do trabalho. Belo Horizonte, 1995. (notas de Aula).

NARONEM, L.; WIKSTROM-GROTELL, C. Professional Theoretical Paper: Towards a paradigm-oriented approach I Physical Therapy. Physical Therapy Theory and Pratice International Journal, n. 3, p. 175-184, 1999.

NASCIMENTO, M.C. et al. A Profissionalização da Fisioterapia em Minas Gerais. Revista Brasileira de Fisioterapia, São Carlos, n. 2, p. 241-247, 2006.

PANHOTRA, B. R.; SAXENA, A. K.; AL-MULHIM, A. S. Hepatitis $B$ vírus vaccination compliance among health care workers in intensive care unit: necessity to improve protection of attending physicians. Intensive Care medicine, n. 11, p. 1596, Nov. 2005.

PORTO, M.F. de S. Uma Ecologia Política dos Riscos: princípios para integrarmos o local e o local na promoção da saúde e da justiça ambiental. Rio de Janeiro: Fiocruz, 2007. 248 p.

PURO, V. et al. Risk of Exposure to Bloodborne Infection for Italian Healthcare Workers, by Job Category and Work Area. Infection Control and Hospital. Epidemiology, n. 4, p. 206-210, Apr. 2001.

RESENDE, M.R.; FORTALEZA, C.M.C.B. Risco ocupacional entre profissionais da área de saúde e medidas de proteção. In: COLIBRINI, M. R. C.; FIGUEIREDO, R. M. de; PAIVA M. C. (orgs.). Leito-dia em AIDS: uma experiência multiprofissional. São Paulo: Atheneu, 2001. p. 139-157. 
RICHARDSON, B. Professional Development. Physiotherapy, n. 9, p. 467-474, Sep., 1999.

SARQUIS, L. M. M. O Monitoramento do Trabalhador de Saúde, após Exposição a Fluidos Biológicos. São Paulo, 2007. 195 f. Tese (Doutorado em Enfermagem). Escola de Enfermagem, Universidade São Camilo, 2007.

SILVA, E. C. B. F. et al. Prevalence and Risk Factors for Staphylococcus Aureus in Health Care Workers at a University Hospital of Recife-PE. Brazilian Journal of Infectious Diseases, Salvador, n. 6, p. 504-508, Dec. 2008.

SIQUEIRA, M. M.; WATANABELL, F. S.; VENTOLA, A. Desgaste Físico e Mental dos trabalhadores de enfermagem: uma análise sob enfoque gerencial. Revista Latino-Americano de Enfermagem, n. 1, p. 45-47, Jan. 1995.

SUCHMAN, L. A. Plans and Situated Actions: The

Problem of Human Machine Communication (Learning in Doing: Social, Cognitive and Computational Perspectives). Cambridge: Cambridge University Press, 1987. 203 p.

THERRIEN, J.; CARVALHO, A.D.F. O professor no Trabalho: Epistemologia da Prática e Ação/ Cognição Situada- Elementos para Análise da Práxis Pedagógica. Revista Brasileira de Formação de Professores, Cristalina, n. 1, p. 129-147, maio 2009. WISNER, A.A Inteligência no Trabalho: Textos Selecionados de Ergonomia. São Paulo: Fundacentro, 1994. 191 p. 